\title{
In vitro growth of calcium pyrophosphate crystals in polyacrylamide gels
}

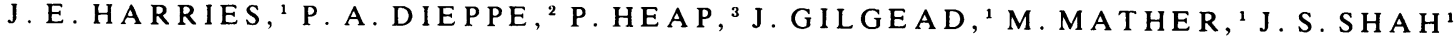 \\ From the University Departments of ${ }^{1}$ Physics, ${ }^{2}$ Medicine, and ${ }^{3}$ Anatomy, Bristol
}

Pyrophosphate arthropathy is characterised by the presence of microcrystalline deposits of calcium pyrophosphate (CPPD) in articular tissues. $^{1}$ The crystals occur in two crystallographic forms-namely, monoclinic (CPPD(M)) and triclinic $(C P P D(T))$. No other crystal species of calcium pyrophosphate has been found in vivo.

This is surprising, as in vitro studies performed under simulated physiological conditions most often yield the orthorhombic form of the tetrahydrate, CPPT(O), ${ }^{2}$ although prolonged incubation may yield $\mathrm{CPPD}(\mathrm{M})$ and $\mathrm{CPPD}(\mathrm{T}){ }^{3}$

Crystal deposition in vivo is restricted to pathological hyaline cartilage, fibrocartilage, and synovium and this has led to speculation that the physicochemical properties of connective tissue are important in nucleation and crystal growth. ${ }^{4}$ In vitro models, using gelatin and silica hydrogels, have therefore been developed in an attempt to represent the physical properties of the tissue matrix. ${ }^{5}$

Using gelatin gels at room temperature we investigated the dependence of the crystal form on the calcium ion concentration and the critical $\mathrm{pH}$. Preliminary studies have revealed local changes in $\mathrm{pH}$ accompanying crystal deposition.

The gels were prepared using the method of Pritzker et al., ${ }^{5}$ whereby a solution of $\mathrm{CaCl}_{2}$ is layered on top of the gel, previously soaked overnight in $2.8 \mathrm{mmol} \mathrm{Na}_{4} \mathrm{P}_{2} \mathrm{O}_{7}$ and the $\mathrm{pH}$ adjusted at $60^{\circ} \mathrm{C}$ using $0.1 \mathrm{~mol}$ $\mathrm{NaOH} / \mathrm{HCl}$.

Using $0.2 \mathrm{~mol} \mathrm{CaCl}_{2}$ resulted in the formation of both $\mathrm{CPPD}(\mathrm{T})$ and CPPT(O) after a period of three weeks. However, careful concentration programming, by which $0.02 \mathrm{~mol} \mathrm{C}_{\mathrm{C}} \mathrm{Cl}_{2}$ is added to the supernatant daily until nucleation occurs (the solution then being made up to $0.2 \mathrm{~mol} \mathrm{CaCl}_{2}$ ) yielded only
CPPD(T) identified by $x$-ray powder diffraction. By varying the initial $\mathrm{pH}$ of the gel from $\mathrm{pH} 5.5$ to $\mathrm{pH} 8.5$ at $60^{\circ} \mathrm{C}$, it was found that growth of $\mathrm{CPPD}(\mathrm{T})$ was favoured by slightly alkaline conditions.

The crystal deposits formed in layers within the gel, collectively known as Liesegang rings. Addition of $\mathrm{BDH}$ universal indicator revealed an increase in acidity with depth of approximately $3 \mathrm{pH}$ units. This increase was not entirely uniform but altered sharply by up to $0.2 \mathrm{pH}$ units, at the edges of the Liesegang rings. These observations imply that crystal deposition is closely linked to the $\mathrm{pH}$ of the immediate surroundings.

A disadvantage of using a gelatin hydrogel as a model system is that it degrades above $30^{\circ} \mathrm{C}$ to become a viscous liquid and is therefore unsuitable for investigating crystal deposition at physiological temperatures.

We have therefore used a polyacrylamide gel which retains its structural properties even above body temperature.

Preparation of the gel involves mixing equal volumes of $2.8 \mathrm{mmol}$ $\mathrm{Na}_{4} \mathrm{P}_{2} \mathrm{O}_{7}$ and $10 \% \mathrm{w} / \mathrm{v}$ polyacrylamide solution (made by dissolving $10 \mathrm{~g}$ polyacrylamide and $0.365 \mathrm{~g}$ NN'dialkyltartardiamide in $100 \mathrm{ml}$ distilled water). Tetramethylethyldiamine $(0.25 \mu \mathrm{l} / 10 \mathrm{ml}$ solution) is added and the pH adjusted to between pH 6 and pH 7 with $10 \mathrm{~N}$ $\mathrm{HCl} / \mathrm{NaOH}$. Polymerisation is induced with $0.25 \mu \mathrm{l} / 10 \mathrm{ml}$ solution of ammonium persalphate. After gelation, typically $10-15$ minutes, neutral $0.2 \mathrm{~mol} \mathrm{CaCl}_{2}$ is carefully poured on top of the gel, which is then incubated at either room temperature or $37^{\circ} \mathrm{C}$ for up to three weeks.

After one week small discrete crystallites were observed throughout the gel, although there was no evidence of any Liesegang rings, so prevalent in gelatin gels. The crystallites were extracted by placing the gel into a continuously stirred $2 \%$ solution of $\mathrm{NaIO}_{4}$ for two hours; the crystals were recovered from solution by filtration.

Optical microscopy performed on the crystallites within the gel revealed two essentially different morphologies; one dendritic, the other spheroidal (or in many cases toroidal) hollow shells.

$X$-ray powder diffraction of crystals grown at room temperature identified the deposits as a mixture of CPPD(T) and CPPT(O), while those crystals deposited at $37^{\circ} \mathrm{C}$ were found to be pure $\mathrm{CPPD}(\mathrm{T})$ within the $\mathrm{pH}$ range 6-7.

The $\mathrm{pH}$ within the gel appeared not to change during the crystal growth process, unlike the situation in gelatin hydrogels.

\section{CONCLUSIONS}

We have shown that a low calcium concentration and an alkaline $\mathrm{pH}$ favour the growth of CPPD(T) crystals in gelatin gels. Using polyacrylamide gels we have found that the temperature of the growth medium is important in deciding the nature of the crystal form and that at $37^{\circ} \mathrm{C}$ pure CPPD(T) can be grown.

Gelatin and polyacrylamide gels show considerably different responses to crystal growth in terms of the formation of Liesegang rings and local $\mathrm{pH}$ variations. In view of these differences it appears that the gel is intimately involved in the crystal growth process. Therefore, careful studies must be made to ensure that current model systems in use are realistic physiological models for crystal deposition in human articular cartilage.

\section{References}

1 McCarty D J. Calcium pyrophosphate dihydrate crystal deposition disease. Arthritis Rheum 1976; 19: 275-85. 
2 Cheng P T, Pritzker K P H, Adams M E, Nyburg S C, Omar S H. Calcium pyrophosphate crystal formation in aqueous solutions. J Rheumatol 1980; 7: 609-16.

3 Hearn P R, Russell R G G. Formation of calcium pyrophosphate crystals in vitro: implications for calcium pyrophosphate crystal deposition disease (pseudogout). Ann Rheum Dis 1980; 39: 222-7.

4 Pritzker K P H, Cheng P T, Omar S A, et al. Calcium pyrophosphate crystal formation in model gels. II. Hyaline cartilage as a gel. J Rheumatol $1981 ; 8$ : 451-5.

5 Pritzker K P H, Cheng P T, Adams M E, Nyberg S C. Calcium pyrophosphate dihydrate crystal formation in model bydrogels.J Rheumatol 1978; 5: 469-73.

\title{
Effect of orthophosphate and other factors on the crystal growth of calcium pyrophosphate in vitro
}

\author{
P. R. HEARN, D. F. GUILLAND-CUMMING, AND R. G. G. RUSSELL \\ From the Department of Human Metabolism and Clinical Biochemistry, University of Sheffield Medical School, Sheffield \\ $S 102 R X$
}

Under simple simulated physiological conditions in vitro we have previously established that $40 \mu \mathrm{mol} / \mathrm{l}$ of pyrophosphate is needed to initiate formation of calcium pyrophosphate crystals in the presence of $1.5 \mathrm{mmol} / \mathrm{l}$ of $\mathrm{Ca}^{++}$at $37^{\circ} \mathrm{C}$ in three days. ${ }^{1}$ If magnesium is added to the system to approach the physiological range $(0 \cdot 5$ $\mathrm{mmol} / \mathrm{l}$ ) the requirement for pyrophosphate rises to $175 \mu \mathrm{mol} / 1$. We have now investigated the effect of another important ion, orthophosphate, over the physiological range, on crystal formation and on long term crystal growth.

Contrary to expectation there was a dose-related decrease in the amount of pyrophosphate needed to initiate the formation of calcium pyrophosphate crystals in the presence of increasing phosphate. At $0.5,1.0$, and 2.0 $\mathrm{mmol} / \mathrm{l}$ phosphate, 125,75 , and 37.5 $\mu \mathrm{mol} / \mathrm{l}$ pyrophosphate are required respectively in the presence of a standard $1.5 \mathrm{mmol} / 1 \mathrm{Ca}^{++}$and 0.5 $\mathrm{mmol} / \mathrm{l} \mathrm{Mg}^{++}$. These results are of particular interest because hitherto it has been thought that pyrophosphate acts as an inhibitor of calcium phosphate crystal deposition. The use of $1 \mathrm{mmol} / \mathrm{l}$ phosphate and $1.5 \mathrm{mmol} / \mathrm{l}$ of calcium with pyrophosphate added creates conditions that are close to physiological and raises the important question of which crystal forms first deposit in vivo. The amount of pyrophosphate $(75 \mu \mathrm{mol} / \mathrm{l})$ needed for crystal growth of calcium pyrophosphate is still higher than the amount of pyrophosphate found in extracellular fluids (normal range 1-4 $\mu \mathrm{mol} / \mathrm{l}$ ) or in synovial fluid in pseudogout (range 5-60 $\mu \mathrm{mol} / \mathrm{l})$. This suggests that under pathological conditions in vivo additional mechanisms may be needed to produce high local concentrations of calcium or $\mathrm{PP}_{\mathrm{i}}$, or that nucleating agents are involved.

Long term incubations at physiological temperature, $\mathrm{pH}$, and ionic strength, with $1.5 \mathrm{mmol} / 1 \mathrm{Ca}^{++}$, $0.5 \mathrm{mmol} / \mathrm{l} \mathrm{Mg}{ }^{++}$and $200 \mu \mathrm{mol} / \mathrm{l}$ pyrophosphate lead, in the absence of phosphate, to the formation of predominantly monoclinic crystals of calcium pyrophosphate. The addition of phosphate at $1 \mathrm{mmol} / 1$ stabilises the amorphous gel that is formed initially, thereby prolonging the time needed for crystal growth. However, it does lead to the formation of much larger crystals. These crystals are of the same type as in the absence of phosphate but differ in that a small proportion of them transform slowly to crystals which appear by optical criteria to be triclinic calcium pyrophosphate dihydrate (the type found in vivo). This indicates that under simulated physiological conditions of $\mathrm{pH}$ and ionic strength and at physiological concentrations of key ions, it is possible to grow the crystal type found pathologically by using high $\left(\begin{array}{lllll}2 & 0 & 0 & \mu \mathrm{mol} / \mathrm{l}\end{array}\right.$ pyrophosphate concentrations.

The possibility that nucleating agents are involved in vivo was explored using crystals of hydroxyapatite or preformed crystals of $\mathrm{CPP}_{1}$ (monoclinic + orthorhombic).
Preliminary results indicate that addition of large numbers of hydroxyapatite crystals $(40 \mu \mathrm{g} / \mathrm{ml})$ raise the concentration of pyrophosphate required for $\mathrm{CPP}_{\mathrm{i}}$ crystal initiation, presumably because they bind pyrophosphate to their surfaces. Lower numbers of added crystals $(4 \mu \mathrm{g} / \mathrm{ml})$ on the other hand had no obvious effect on the initiation of $\mathrm{CPP}_{\mathrm{i}}$ crystals, suggesting that any surface binding effect was compensated by a promoting effect on nucleation.

In long term incubations $(>2$ months) neither added hydroxyapatite nor added $\mathrm{CPP}_{\mathrm{i}}$ crystals altered the type of new $\mathrm{CPP}_{i}$ crystals formed. Both types of crystals considerably accelerated $\mathrm{CPP}_{\mathrm{i}}$ crystal formation in the presence of excess $\mathrm{PP}_{\mathrm{i}}(100-300$ $\mu \mathrm{mol} / \mathrm{l})$ both in the presence and absence of phosphate.

In conclusion, it has not yet been possible to grow the pathological $\mathrm{CPP}_{\mathrm{i}}$ crystal type (triclinic) in short term culture in vivo under simulated physiological conditions. Such crystals do, however, appear in long term incubations $\left(\frac{1}{2}-2\right.$ years $)$, supporting the suggestion that their presence in chondrocalcinosis represents the end point of a gradual process.

\section{Reference}

1 Hearn P R, Russell R G G. Formation of calcium pyrophosphate crystals in vitro: implications for calcium pyrophosphate crystal deposition disease (pseudogout). Ann Rheum Dis 1980; 39: 222-7. 